\title{
Effects of Amino Acids on Iron-Silicate Chemical Garden Precipitation
}

\author{
Michelle R. Hooks ${ }^{1}$, Paul Webster ${ }^{2}$, Jessica M. \\ Weber $^{1 *}$, Scott Perl ${ }^{1}$, Laura M. Barge ${ }^{1}$ \\ Supplemental Information
}




\section{Table of Contents}

I. Images of Sample Prep S-3

II. Additional Chemical Garden Images S-4

III. ${ }^{1} \mathrm{H}$ NMR Spectra $\quad$ S-8

IV. Additional SEM Images S-13 


\section{Images of Sample Prep}

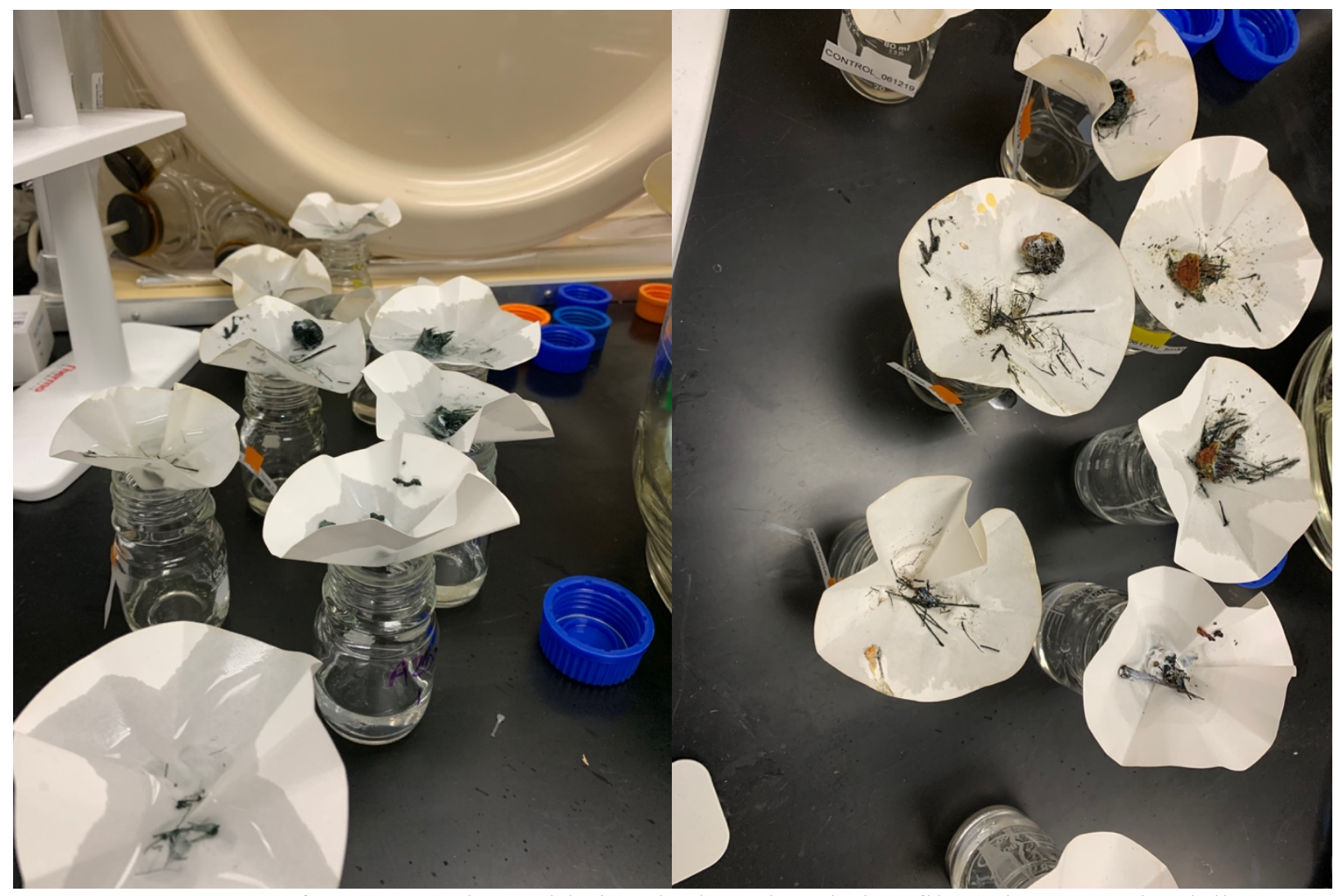

Figure S1. Images of $20 \mathrm{mM}$ amino acid chemical gardens being filtered. Due to the delicate nature of the chemical garden, the choice of filter paper proved to be important. We attempted to recover a variety of morphologies for SEM.

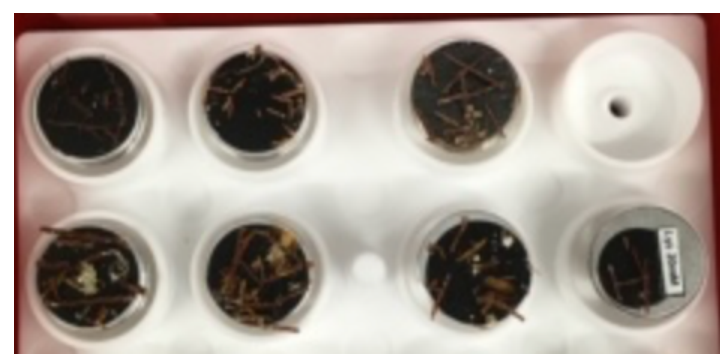

Figure S2. Image of chemical gardens mounted for SEM. 


\section{Additional Chemical Garden Image}

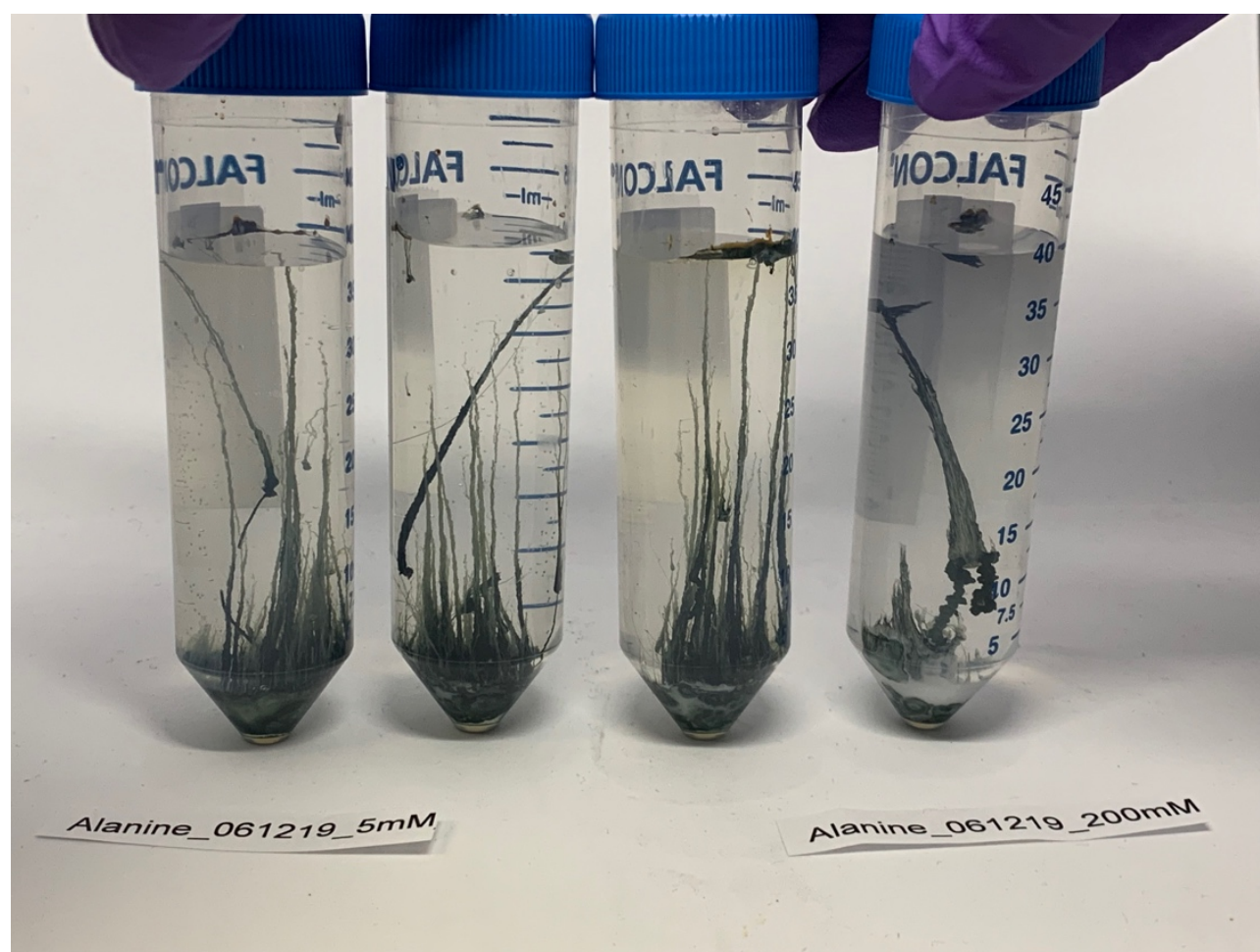

Figure S3. Image of chemical gardens grown with $5 \mathrm{mM}, 10 \mathrm{mM}, 50 \mathrm{mM}$, and $200 \mathrm{mM}$ aniline.

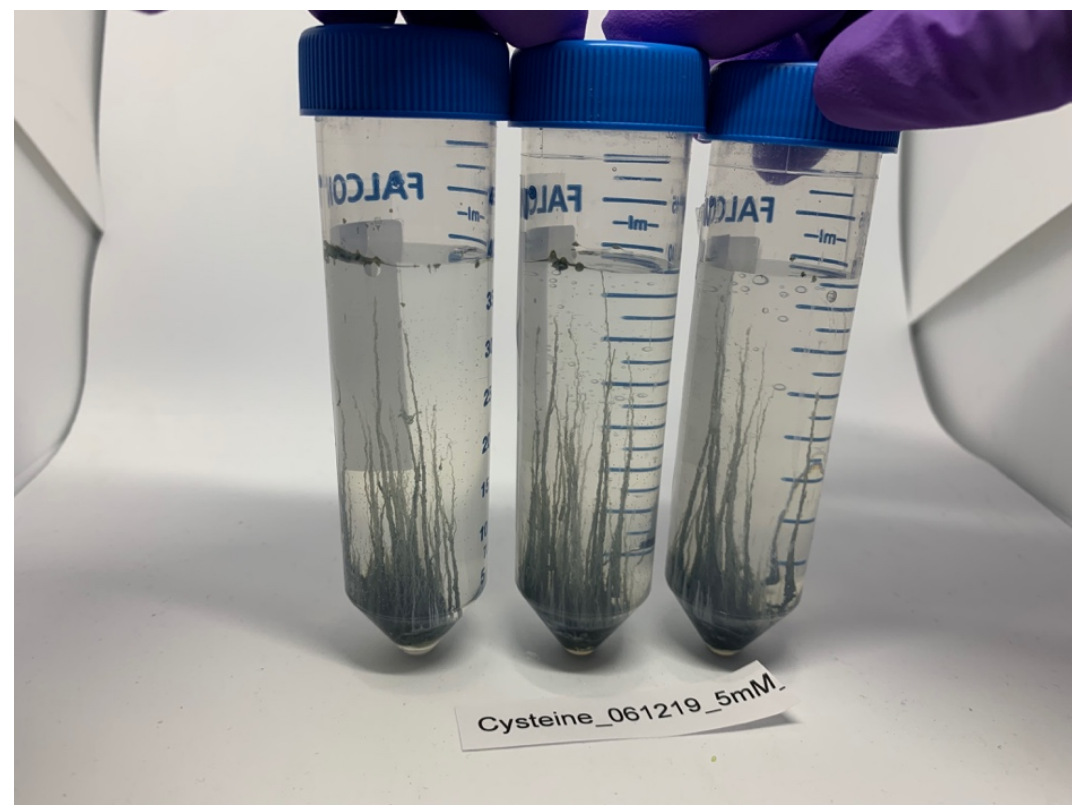

Figure S4. Image of 3 chemical gardens grown with $5 \mathrm{mM}$ cysteine. 


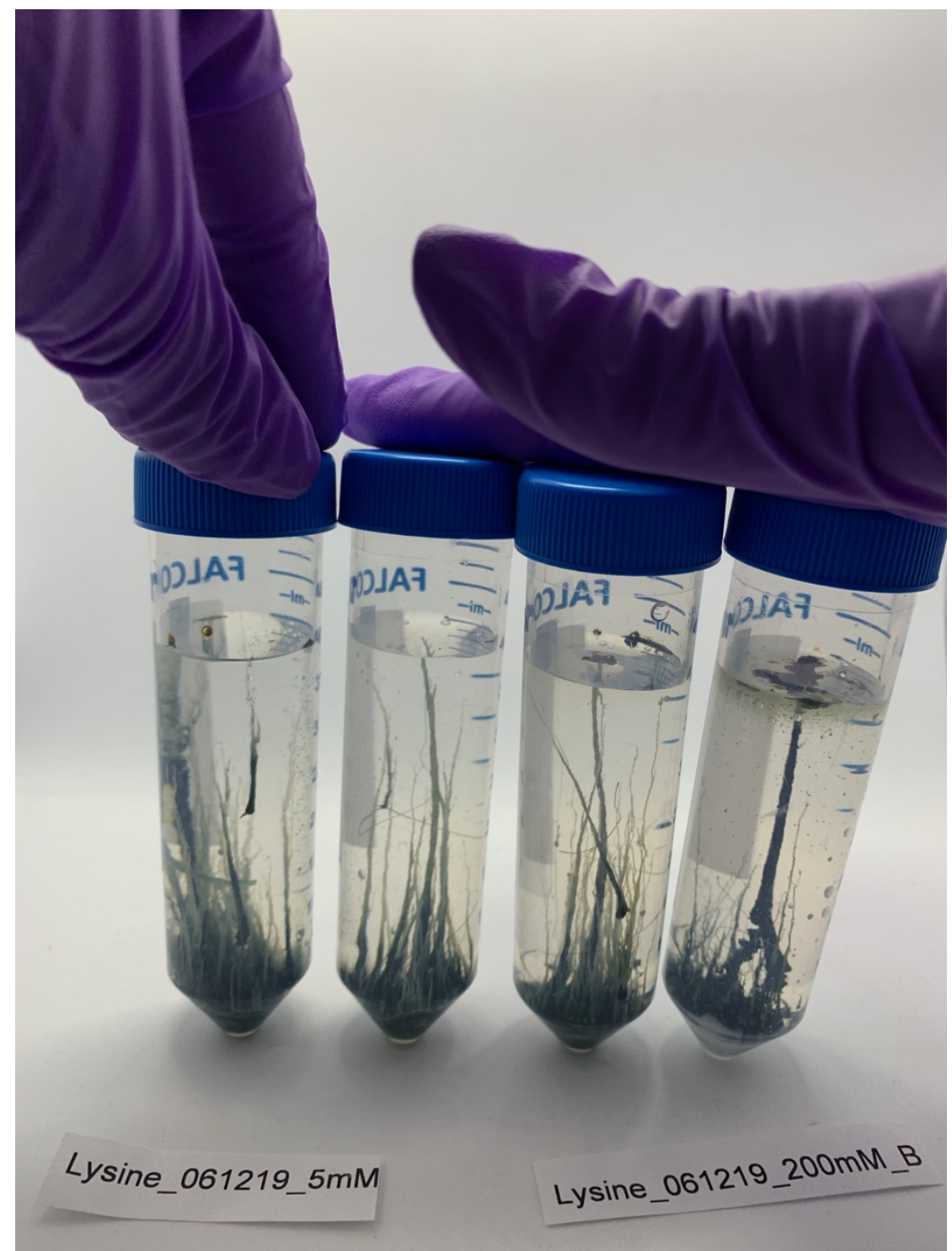

Figure S5. Image of chemical gardens grown with $5 \mathrm{mM}, 10 \mathrm{mM}, 50 \mathrm{mM}$, and $200 \mathrm{mM}$ lysine. 


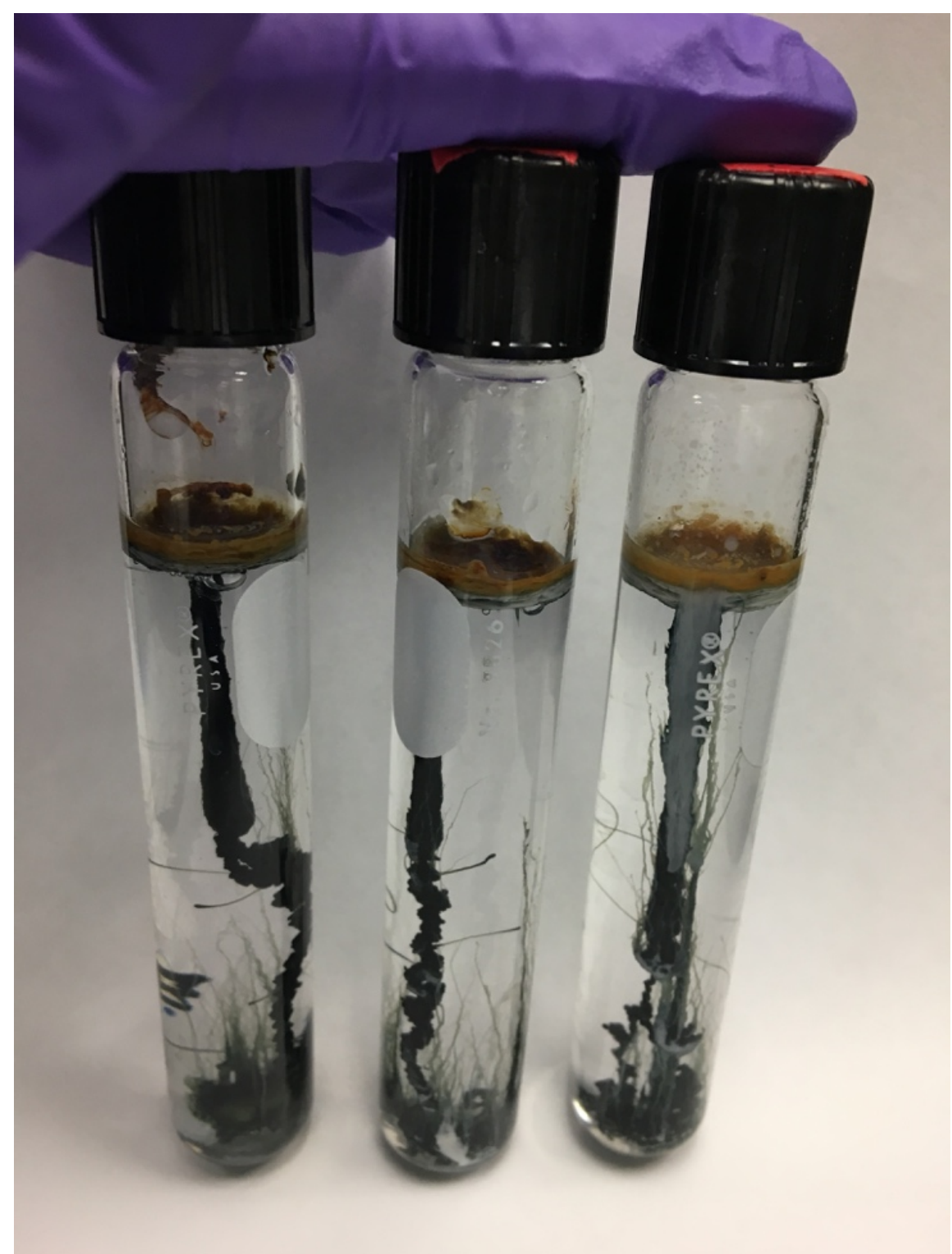

Figure S6. Image of three chemical gardens grown with $50 \mathrm{mM}$ aspartic acid. 


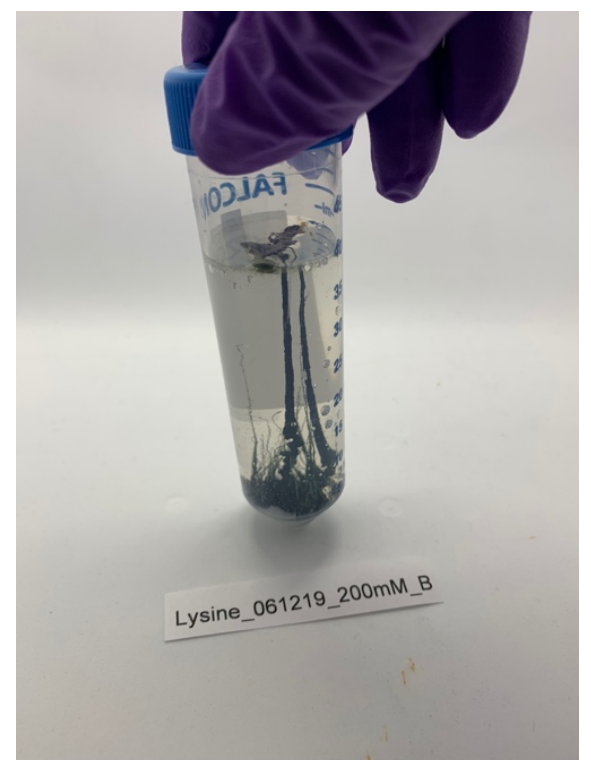

Figure S7. Image of chemical gardens grown with $200 \mathrm{mM}$ lysine.

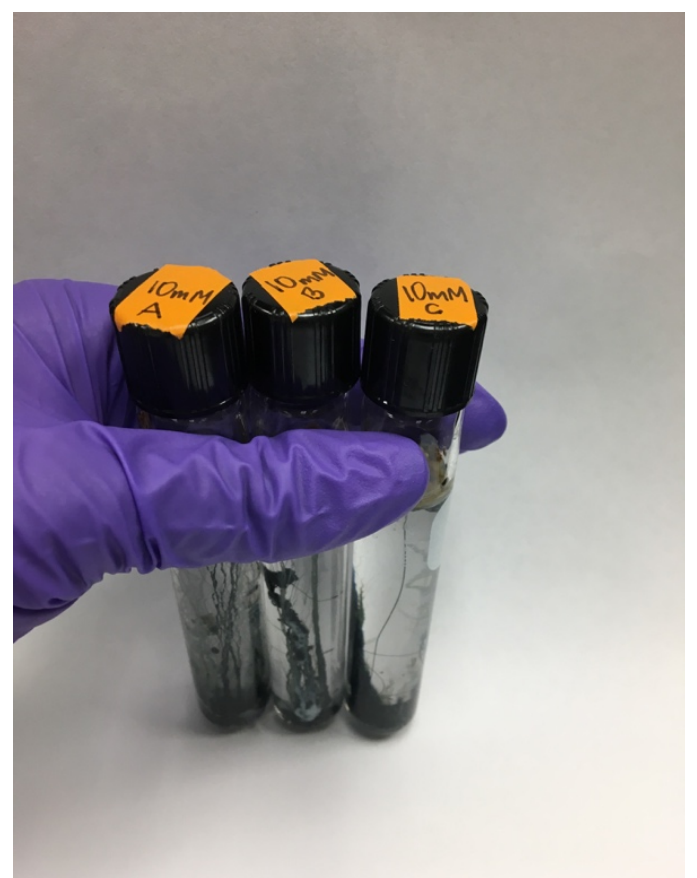

Figure S8. Image of three chemical gardens grown with $10 \mathrm{mM}$ aspartic acid. 


\section{III. ${ }^{1} \mathrm{H}$ NMR Spectra.}

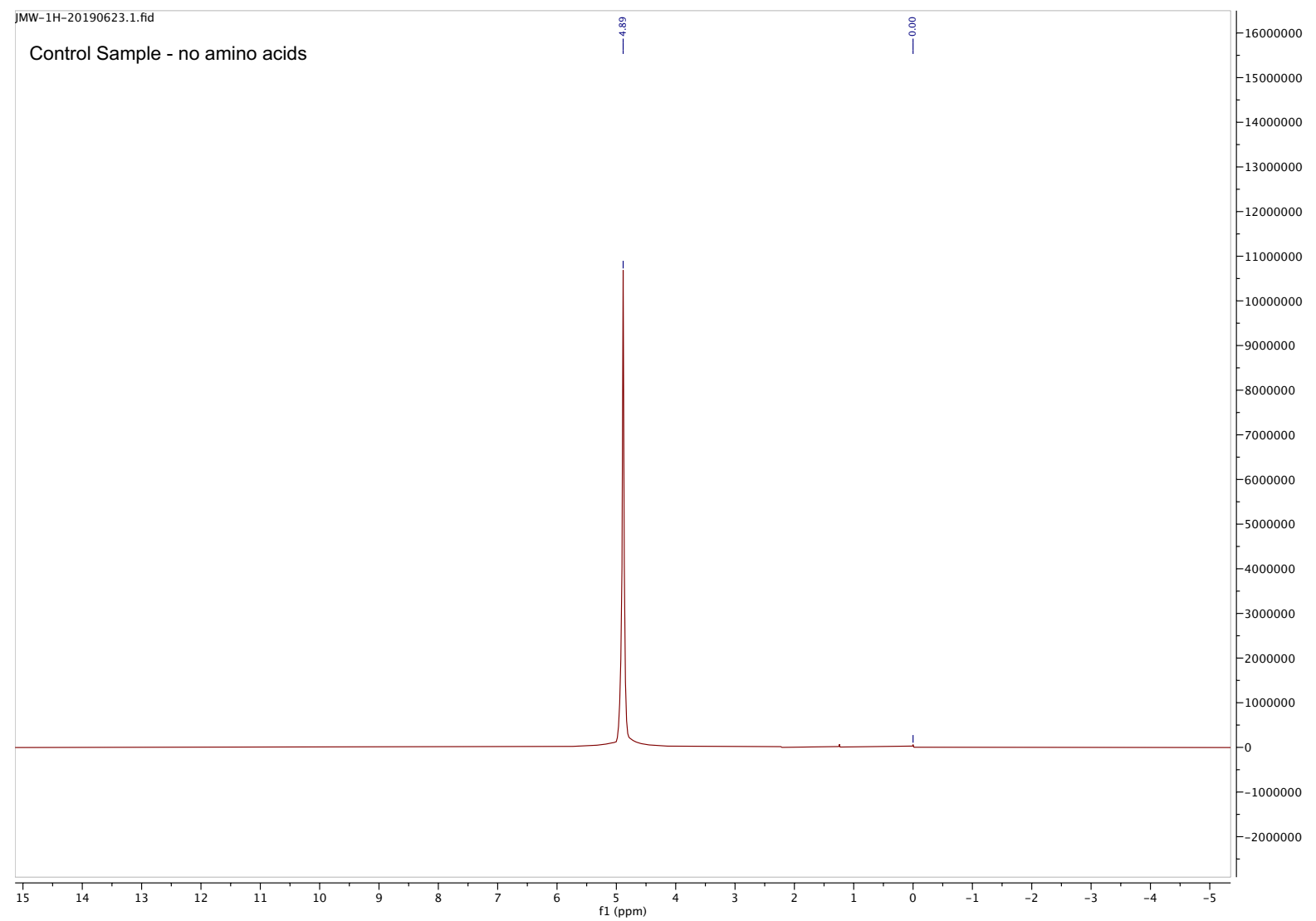

Figure S9. ${ }^{1} \mathrm{H}$ NMR of solution of control chemical garden (no amino acid). 


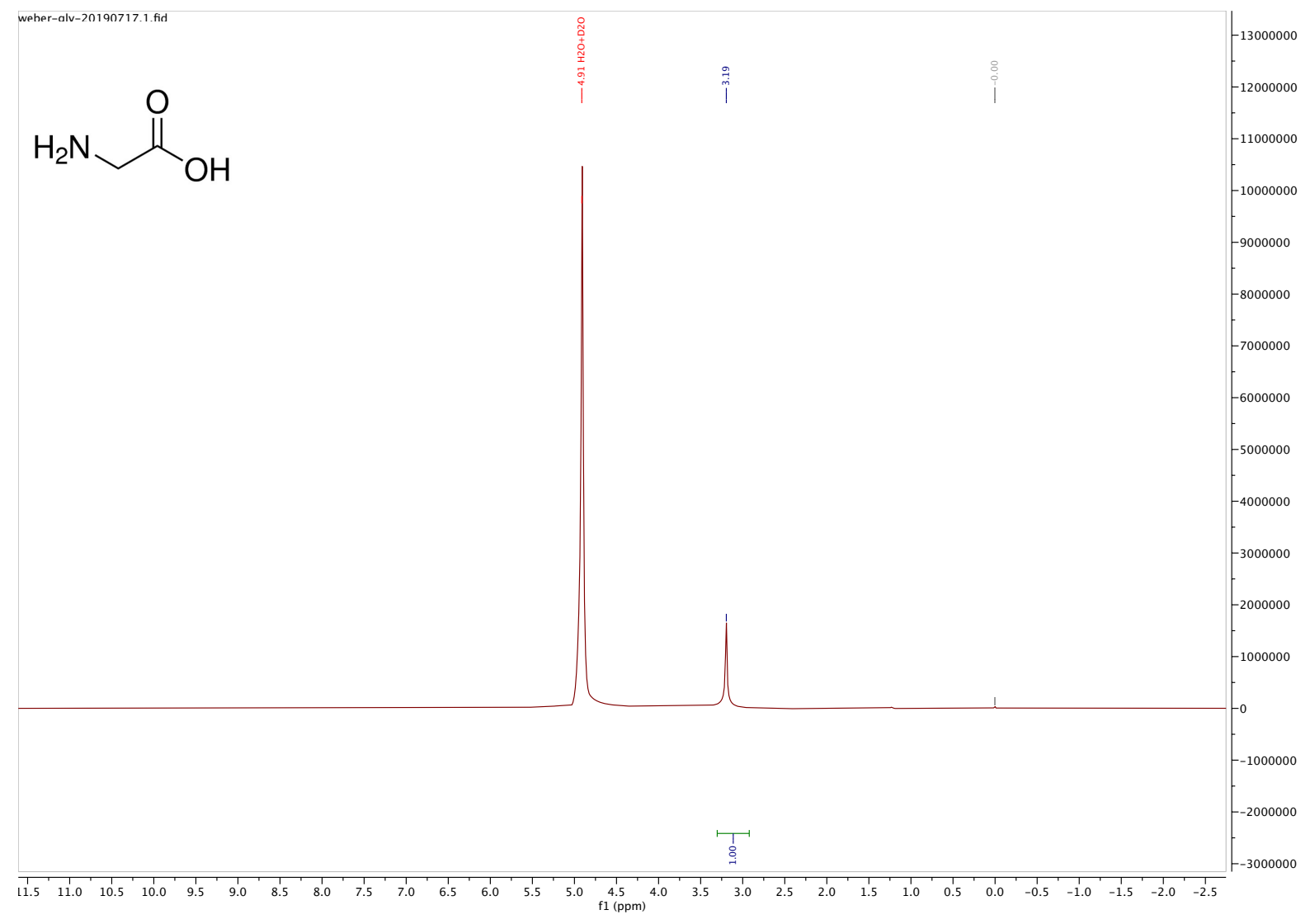

Figure S10. ${ }^{1} \mathrm{H}$ NMR of solution of chemical garden grown with $20 \mathrm{mM}$ glycine. 


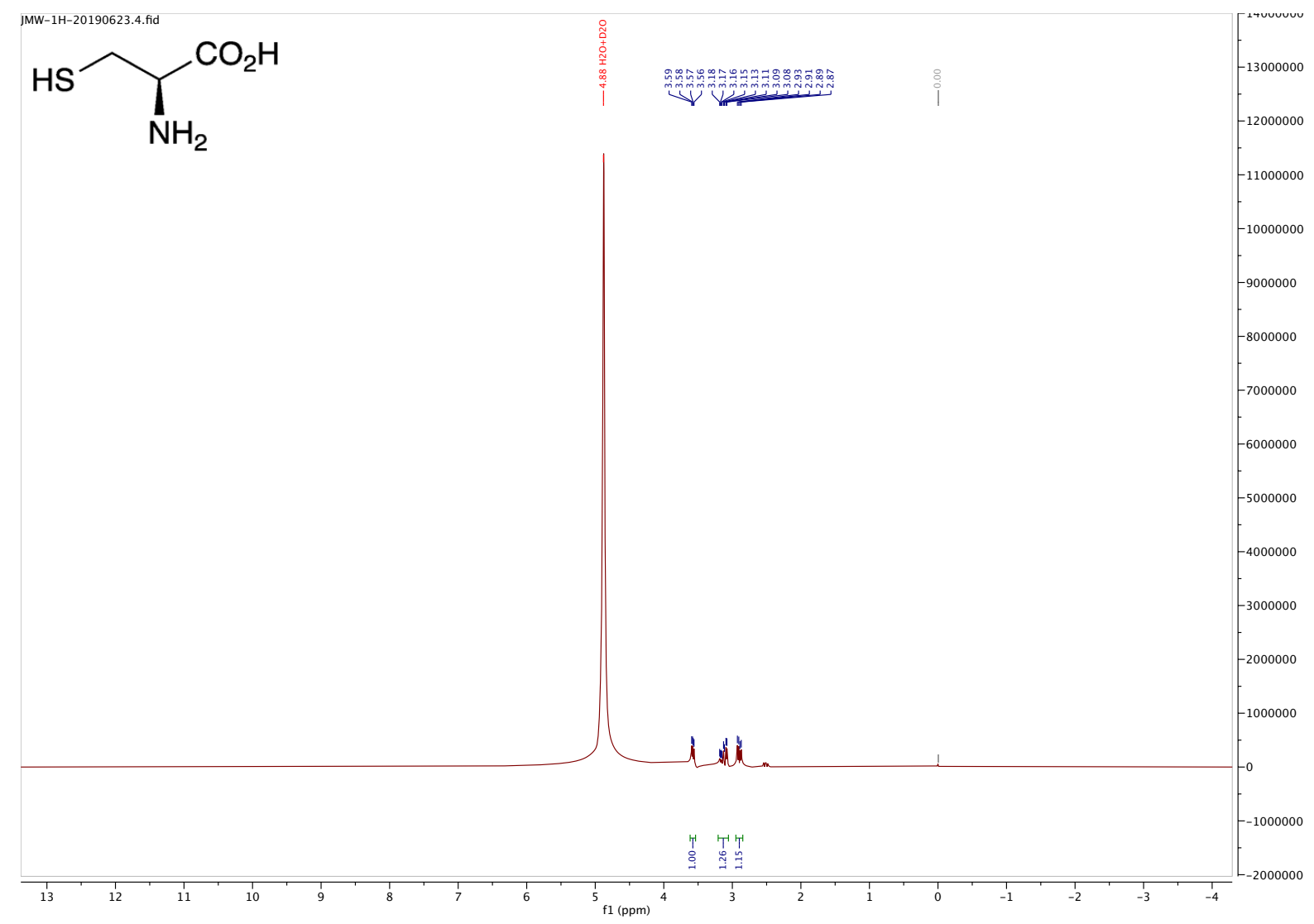

Figure S11. ${ }^{1} \mathrm{H}$ NMR of solution of chemical garden grown with $20 \mathrm{mM}$ cysteine. 


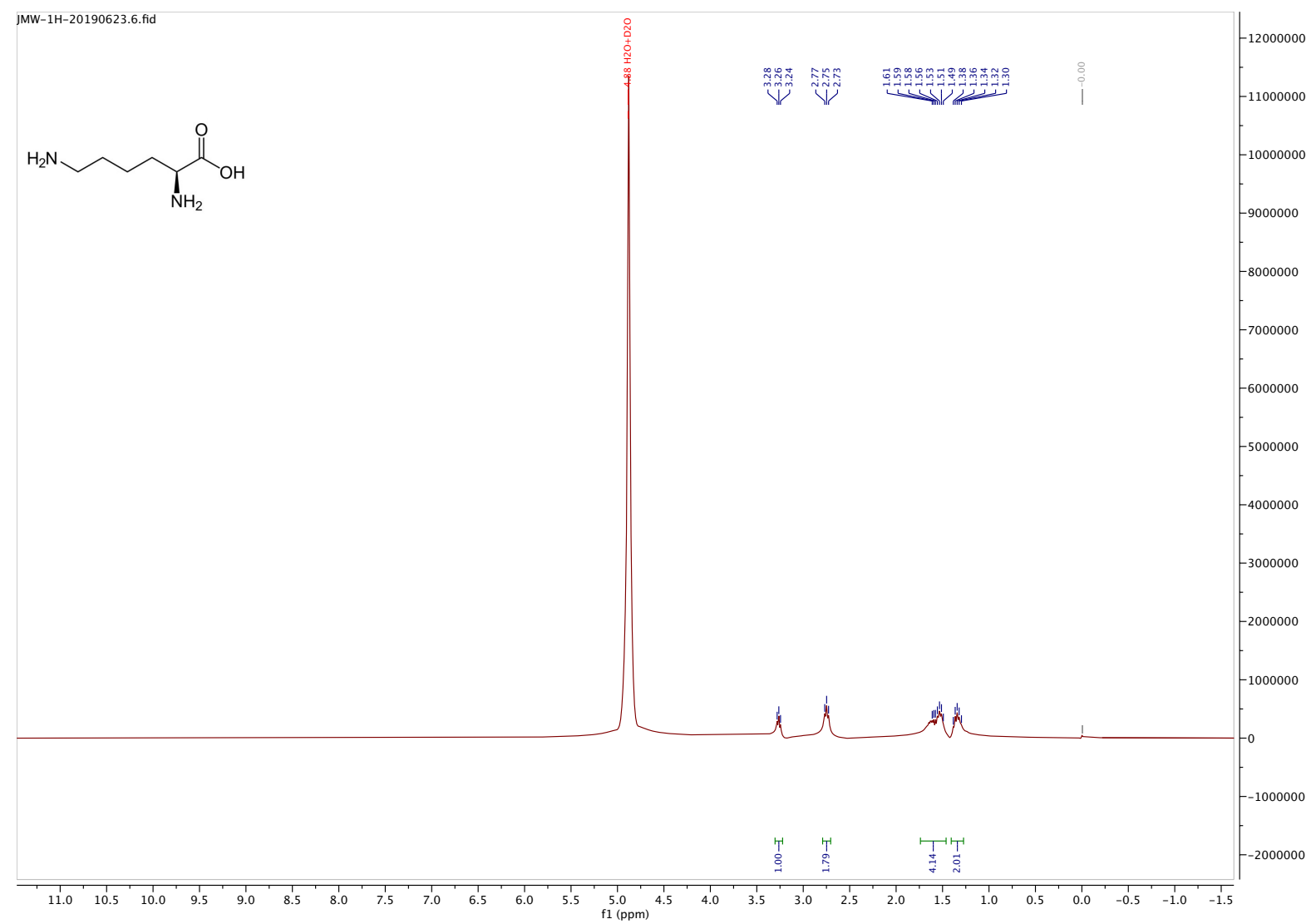

Figure S12. ${ }^{1} \mathrm{H}$ NMR of solution of chemical garden grown with $20 \mathrm{mM}$ lysine. 


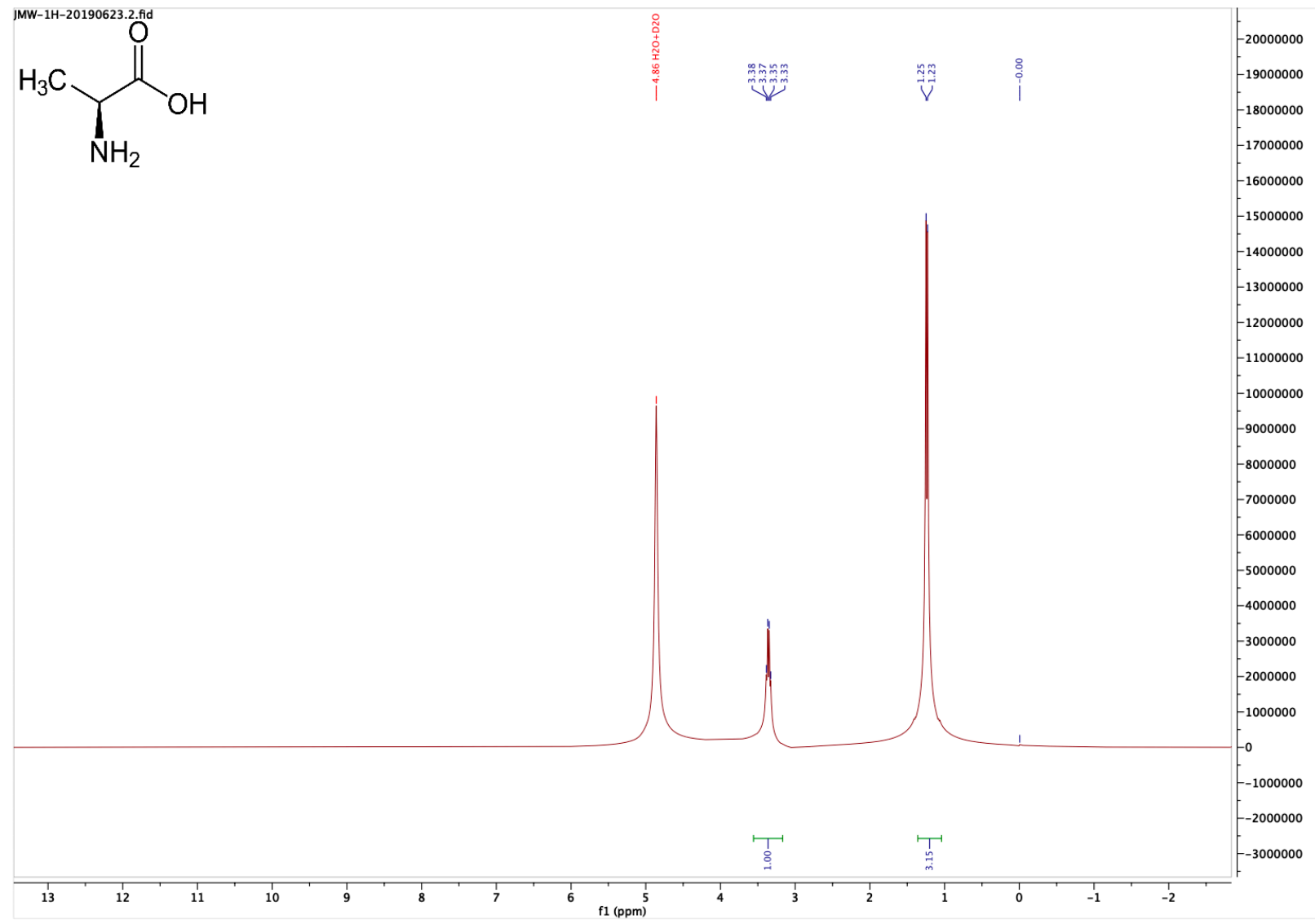

Figure S13. ${ }^{1} \mathrm{H}$ NMR of solution of chemical garden grown with $20 \mathrm{mM}$ alanine. 


\section{Additional SEM Images}

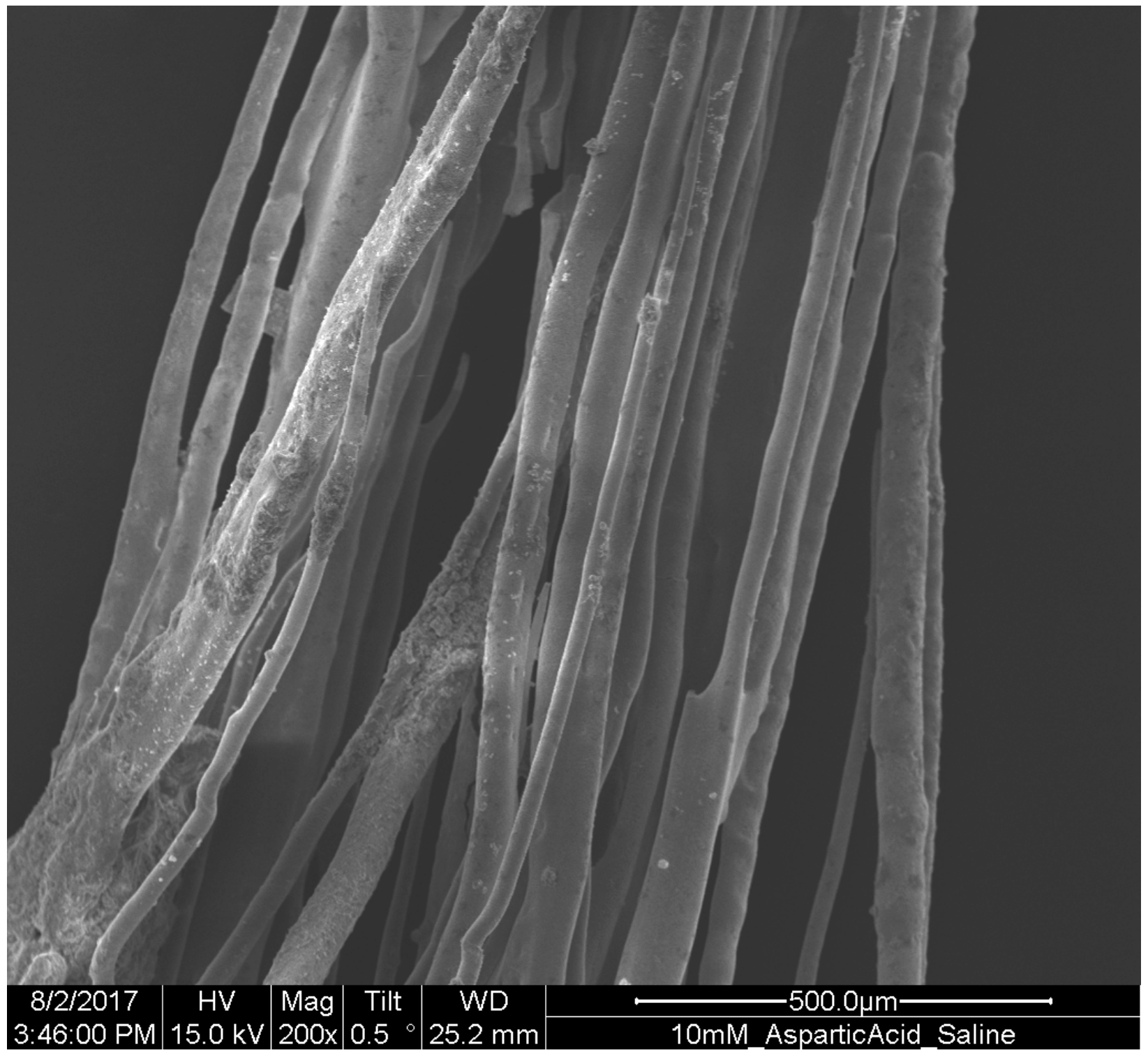

Figure S14. SEM Image of chemical garden grown with $10 \mathrm{mM}$ aspartic acid. 


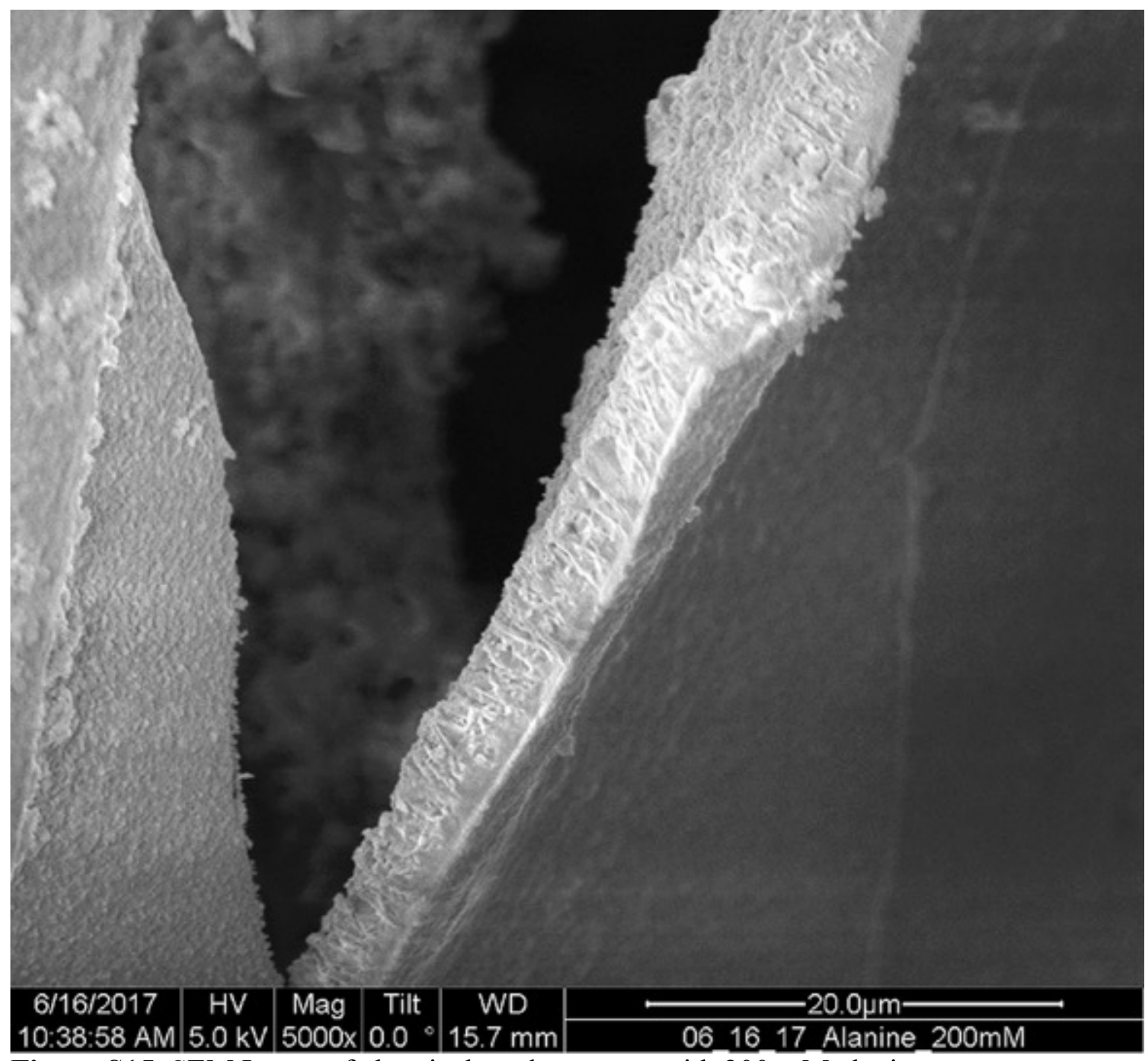

Figure S15. SEM Image of chemical garden grown with $200 \mathrm{mM}$ alanine. 


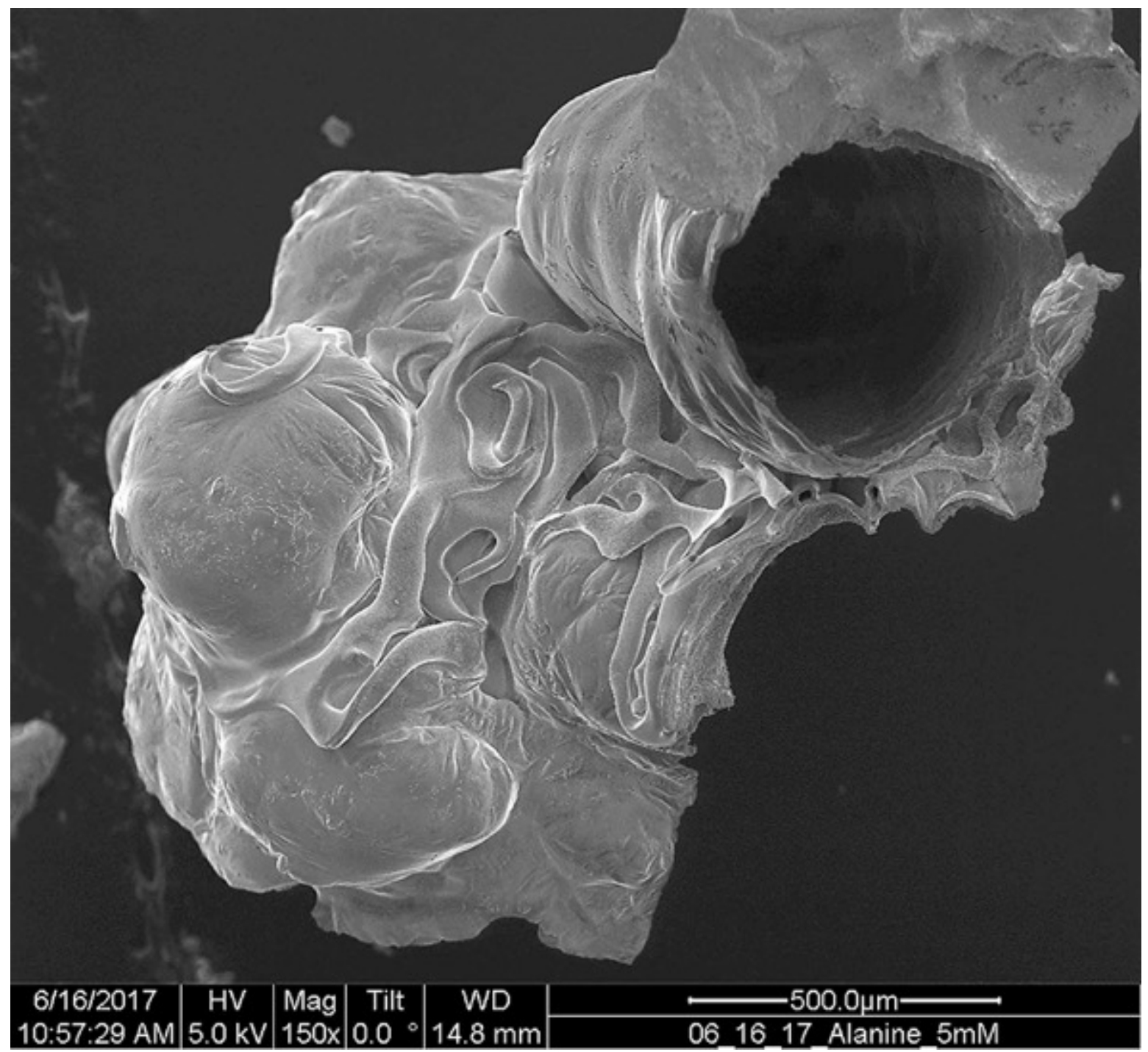

Figure S16. SEM Image of chemical garden grown with $5 \mathrm{mM}$ alanine. 


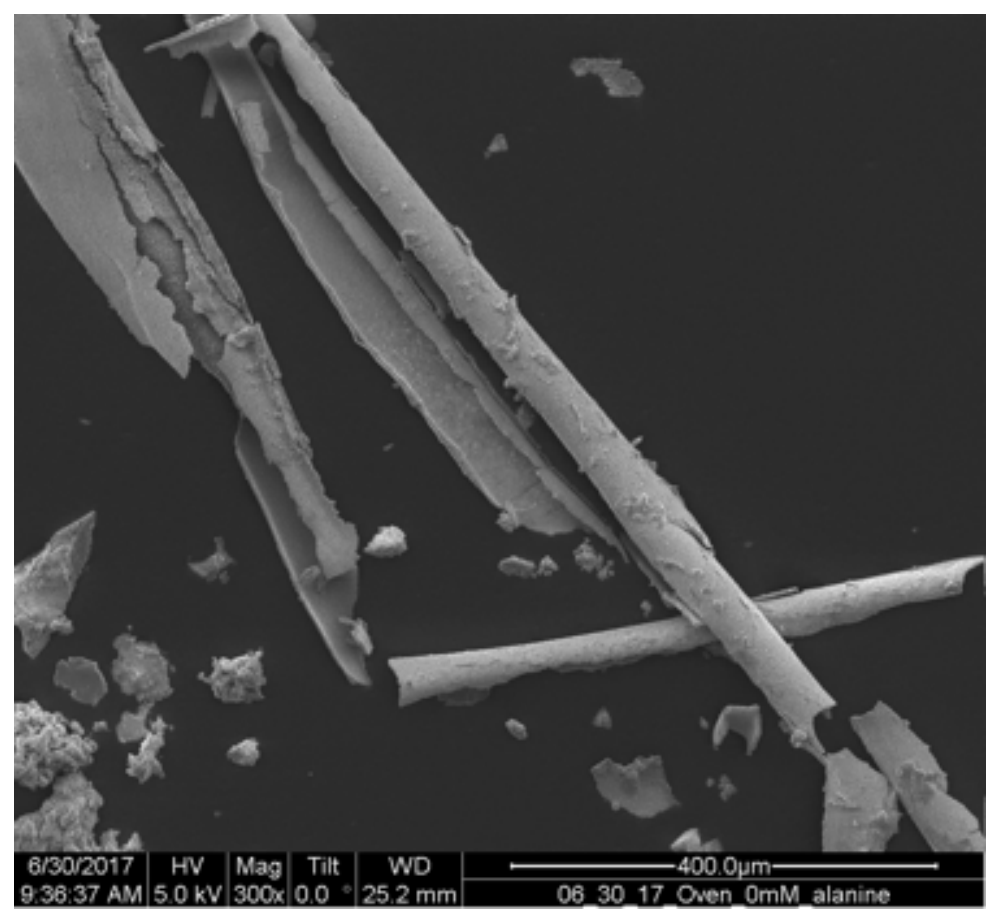

Figure S17. SEM Image of control chemical garden without new workup techniques. Significant damage was done without proper workup techniques.

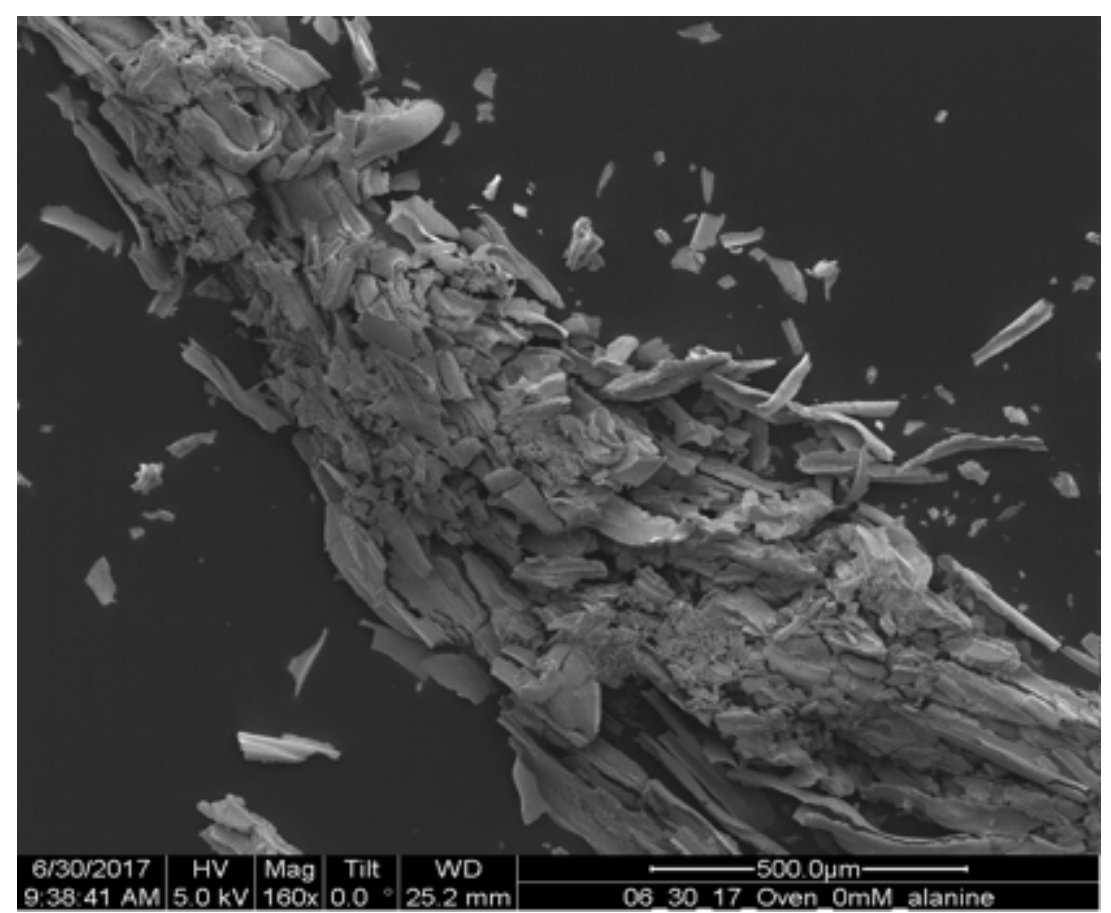

Figure S18. SEM Image of control chemical garden without new workup techniques. Significant damage was done without proper workup techniques. 